\title{
A abertura da saúde nacional ao capital estrangeiro: efeitos do mercado global no Brasil
}

\author{
The opening of the national healthcare market to Foreign Direct \\ Investment: effects of the global market in Brazil
}

Jonathan Filippon $\mathbf{1}^{2}$

\begin{abstract}
RESUMO A saúde é um direito constitucional no Brasil. Este ensaio debate a abertura do mercado da saúde, em seu subsistema privado, ao investimento estrangeiro (Foreign Direct Investment), sancionada pelo governo brasileiro (Lei 13.097/2015). Busca evidências na literatura que demonstrem experiências semelhantes em outros países, assim como contextualiza o mercado da saúde nacional na conjuntura global de investimento em serviços. Tal lei, carecendo de mecanismos regulatórios e de discussões prévias nas instâncias de controle social, falhará na promoção de maior competitividade entre provedores e acarretará, como consequência de longo termo, a inviabilidade do subsistema público de saúde nacional.
\end{abstract}

PALAVRAS-CHAVE Saúde; Sistema Único de Saúde; Política pública de saúde.

ABSTRACT Health is a constitutional right in Brazil. This essay debates the opening of the healthcare market, in its private subsystem, to foreign investment (Foreign Direct Investment), sanctioned by the Brazilian government (Law 13097/2015). It searches for evidence in the literature which demonstrate similar experiences in other countries, as well as contextualises the national healthcare market in the global services investment setting. This Law, lacking regulatory mechanisms and previous discussions in social control instances, will fail in the promotion of greater competition among providers and will entail, as a long term consequence, the unviability of the national public health subsystem.

KEYWORDS Health; Unified Health System; Public health policy.

1 Queen Mary University of 


\section{Introdução}

Saúde é um direito constitucional no Brasil, um dever do Estado junto aos cidadãos. A afirmativa baseia-se na Constituição Federal e na Lei 8.080 (BRASIL, 1990), e é, no mínimo, contraditória, se colocada no contexto da globalização do comércio mundial. Grosso modo, a Constituição destina ao Estado a responsabilidade de oferecer algo que, de acordo com o entendimento neoliberal, pode ser adquirido no mercado por qualquer cidadão, desde que este possua as condições financeiras para tanto. Há, portanto, na Constituição do Brasil, a escolha ético-política, pelo paradigma de que a saúde é um direito e não um produto, sendo assim, inerente a todo cidadão brasileiro. Estaria, então, o Brasil na contramão do comércio mundial?

A promoção do mercado livre e irrestrito vem sendo capitaneada pela Organização Mundial do Comércio (OMC), da qual o Brasil é país signatário desde sua criação, assim como grande parte das nações do mundo, a partir de 1994/95. O estabelecimento de uma agência supragovernamental para regular e promover o livre comércio, há cerca de 20 anos, foi o marco de um processo iniciado décadas antes, imediatamente após o término da Segunda Guerra Mundial, quando os Estados Unidos (EUA) tornaram-se dominantes nas relações de mercado mundiais. Depois de promover a recuperação comercial dos Estados Europeus afetados pelo conflito mundial, dos anos 1940, os EUA tornaram-se os bastiões do livre comércio e da movimentação do capital, um lugar anteriormente ocupado pela Inglaterra colonialista. Apesar da chamada globalização da economia estar inicialmente restrita à liberalização das commodities físicas (physical goods), o setor de serviços vem, desde a metade da década de 1990, aumentando sua participação nas relações econômicas internacionais, sendo considerado o setor da economia internacional de maior taxa proporcional de crescimento (JARMAN, 2014).
No mercado mundial, o Brasil é apenas uma entre muitas bancas de uma feira de rua, em que produtos possuem uma etiqueta com preço e uma possível margem de lucro anexada. Esses são, tecnicamente, considerados commodities, em outras palavras, produtos/serviços que se tornam algo passível de sofrer ação comercial de compra/ venda. Alguns desses 'produtos', no entanto, são parte do ethos coletivo civilizatório da população, preservando direitos horizontais básicos que independem de renda, cor, idade ou gênero dos que são, em última instância, os donos da banca. O mercado da saúde era, até o ano de 2015, um exemplo desse tipo de commodity no Brasil - um direito constitucional preservado do assédio do capital externo (parcialmente, pois alguns seguros de saúde brasileiros já possuem papéis negociados internacionalmente). Apesar de fazer parte desse mercado mundial, na banca do Brasil, a saúde era um produto protegido e reservado aos brasileiros. Era ou ainda é?

Nesse mercado de rua virtual não há espaço para avaliações qualitativas, morais ou éticas - e a cortina de fumaça da ideologização política colabora para manter a necessidade vazia da retidão e da precisão numérica do que é mais lucrativo, eficaz (e não necessariamente efetivo) e barato. Causa espécie o afastamento de necessárias discussões éticas a respeito de assuntos relativos à coletividade da vida política, suas regras e entendimentos sobre o que pode ser explorado com o objetivo de lucro e o que deve ser preservado por sua característica de interesse comum. Neste sentido, a possibilidade de escolher o consumo de produtos relativos à saúde fica condicionada à ocorrência ou não de agravos (doenças), parte natural do ciclo da vida. Portanto, não há escolha com relação a definições. Saúde é um interesse comum, e seu uso como catalisador de margens de lucro deve ser cautelosamente discutido com todos os interessados.

Apesar disso, em 19 de janeiro de 2015, foi sancionada a Lei 13.097/2015 (BRASIL, 2015), 
que altera a Lei 8.080 (BRASIL, 1990), em conjunto com outras decisões não relacionadas ao mercado da saúde e aos seus interesses. Em poucas palavras, tal lei abre o mercado brasileiro à participação do capital estrangeiro sem restrições, chamando a atenção para o fato de uma decisão de tal magnitude ter sido tomada sem negociações nas instâncias de controle social, principalmente o Conselho Nacional de Saúde. De uma prateleira fechada da Banca Brasil a um tabuleiro posto no chão, ao alcance de todos os players do global market, o mercado brasileiro da saúde foi aberto e está, neste momento, oferecido de bandeja a quem puder pagar mais.

Este ensaio baseia-se em evidências de outros países que passaram ou estão passando por experiência semelhante, no setor da saúde ou em outros serviços, avaliando, assim, as possíveis consequências que a citada modificação na Lei Orgânica da Saúde brasileira pode acarretar. Evita-se aqui a cortina ideológica, binária e reducionista da polarização entre certo e errado, buscando evidências em peer review journals indexados e relevantes para o tema, baseando a discussão nas evidências encontradas. Em um segundo momento, propõem-se alternativas cabíveis neste prelúdio, ainda a partir das evidências internacionais de nações que, assim como o Brasil, propõem-se a considerar a saúde e o cuidado em saúde como um direito fundamental e inalienável de seus cidadãos.

\section{O mercado global e o Welfare State europeu}

A abertura dos serviços de saúde ao livre comércio é parte de uma composição maior, na qual a saúde é apenas uma das commodities a ser 'liberalizada', um movimento globalmente estabelecido a partir da fundação da Organização Mundial do Comércio (OMC), em 1995 (WALLACH; WOODALL, 2004). A imagem-objetivo da organização tem sido a liberalização de bens e serviços como commodities em um mercado com a menor participação possível de regulamentações/ restrições público-governamentais. Os tratados de livre comércio da OMC podem ser considerados como o paralelo equivalente à declaração de direitos humanos, contudo, desta vez, os beneficiados são o empresariado e os grandes proprietários do capital financeirO (PRICE; POLLOCK; SHAOUL, 1999). O levantamento de dados a respeito dessa relação é dificultado por discussões ideológicas que ofuscam/afastam a opinião pública das discussões. Esse fenômeno é observado em vários países em que a sociedade é pasteurizada em uma única imensa massa de consumidores acríticos - relação essa continuamente menos questionada e ultimamente encarada pela 'geração Y' como a 'ordem natural das coisas'.

A diminuição (ou extinção) de barreiras ao comércio de bens e serviços é o horizonte utópico liberal, horizonte objetivo de teorias sociais que centram a vivência humana no indivíduo e na sua, unicamente sua, liberdade de escolha - independentemente da (con)vivência na polis (VANBERG, 2014). Em oposição às teorias que embasaram as escolhas políticas de vivência comum do pós-guerra, nas décadas de 1940 e 1950, as quais originaram o Welfare State europeu e seu embasamento teórico/prático de compartilhamento de riscos (risk sharing), aquelas estão baseadas em argumentos técnico-administrativos, como o New Public Management, Parcerias Privadas de Financiamento, teoria do Estado mínimo, entre outros (ALONSO; CLIFTON; DíAZ-FUENTES, 2015).

A este ensaio interessa a relativamente recente criação de mecanismos que possibilitam a obtenção de valores referentes ao gasto público em saúde por setores da iniciativa privada, um fenômeno global possibilitado pela participação de empresas transnacionais apoiadas em mecanismos de transferência de capital. Apesar das poucas evidências, chamam a atenção os casos dos 
países europeus, nos quais o gasto público em saúde aproxima-se da totalidade do gasto total, variando entre 5 e $12 \%$ do PIB (Produto Interno Bruto ou Gross Domestic Product GDP) desses países (REEVES ET AL., 2014).

Seguindo a história das nações, o paradoxo financeiro é, além de pano de fundo, um intenso vento que controla as correntes dos acontecimentos. Devido à crise capitalista de produção enfrentada a partir do final das décadas de 1970 e 1980, os mercados americanos, o motor capitalista global, voltaram-se ao setor de empregos e serviços como possibilidade real de lucro. Em uma versão globalizada e simplista da mais-valia da era industrial, agora a partir da exploração do gasto público em serviços de uso comum da população, o mercado global voltou-se ao setor de serviços. O chamado Gats (General Agreement on Trade in Services) cobre acordos de comércio de serviços em telecomunicações, transporte, distribuição de produtos, serviços postais, seguros, meio ambiente, turismo, entretenimento e lazer. Além desses, os serviços (agora produtos) incluem: cuidado à saúde, serviço social, educação, habitação, entre outros. Boa parte desses serviços é administrada e paga com dinheiro público, como o caso do Welfare State europeu, ou parcialmente dividida entre os setores público e privado, caso de países tardiamente industrializados como o Brasil e alguns países asiáticos. O processo de escolha sobre quais serviços serão liberalizados e quais mercados serão protegidos é negociado em cada round da OMC, dando ênfase a quatro aspectos de cada nicho de mercado: oferta entre fronteiras, consumo externo, presença comercial de entes jurídicos e presença de pessoas físicas. No final da década de 1990, anunciava-se o que estaria por vir a partir da virada do milênio com relação ao Welfare State europeu e seu 'custo':
Governments in Europe and the US link the expansion of trade in public services to success, and, with the backing of powerful coalitions of transnational and multinational corporations, 'the race is on to capture the share of gross domestic product governments currently spend on public services (PRICE; POLLOCK; SHAOUL, 1999, P. 1890, GRIFO DO AUTOR).

Já anteriormente, a Coalition for Service Industries americana havia mencionado que a principal dificuldade dos empresários em explorar o setor saúde fora dos Estados Unidos era o controle estatal presente em outros países, tanto na Europa quanto em outros mercados menos promissores naquele momento (KOIVUSALO; TRITTER, 2014). No Brasil, a ascendente e disforme classe média culturalmente rejeita a oferta pública de serviços, considerados de menor qualidade, convencida de que mediante pagamento, exercendo sua livre escolha no mercado, receberá o melhor produto de acordo com sua necessidade - um alvo em potencial para o capital, externo ou interno, no tocante ao mercado da saúde.

\section{A liberalização gradativa, porém constante, do capital público}

Durante a década de 1990, os investimentos em saúde nos EUA, realizados em Wall Street, tiveram lucro recorde, de cerca de US\$ 700 milhões, em 1996, seguidos da perda recorde acumulada de US\$ 768 milhões, em 1998. As perdas deram-se, principalmente, pela saturação do mercado e pelo aumento das restrições comerciais (regulamentação do setor), ocasionando diminuição de prêmios pagos e enfoque em nichos de mercado que ofereciam maiores margens de lucro (POLLOCK; PRICE, 2013). Além disso, a indústria recebeu o 
auxílio do Banco Mundial e do governo americano para incentivar a política de investimentos externos, principalmente a aquisição de serviços públicos de saúde dentro ou fora do território americano. $\mathrm{O}$ alvo dessas ações é a busca do multibilionário financiamento público de fundos, os chamados tax pools, responsáveis pelos financiamentos nacionais dos sistemas de saúde e seguridade social. No caso da saúde, definir tecnicamente o significado das mudanças na forma de financiamento de serviços é, mesmo para especialistas, uma tarefa difícil. Há, porém, acordo ao afirmar que "tax pools are effectively privatised when public health care is redirected through private-sector organisations" (PRICE; POLLOCK; SHAOUL 1999, P. 1890). A expansão do mercado global da saúde depende diretamente da abertura de mercados atualmente controlados pelo setor público, como no caso europeu, de partes da Ásia e parcialmente da América do Sul.

Para vencer restrições e regulamentações, o movimento do capital para fora do sistema e do controle público é gradativo, nomeado tecnicamente e justificado por razões administrativas de gestão e eficácia de gastos. No caso do National Health Service inglês (NHS), os principais pontos de mudança apontados foram:

1. As mudanças na alocação de recursos iniciadas na era Tatcher (outsorcing): por meio da terceirização parcial de serviços, como limpeza, e da abertura de pontos comerciais em hospitais públicos, como cafés e lanchonetes. É considerada como o marco de entrada da participação privada no $N H S$;

2. Imposição de Contabilidade Comercial às Primary Care Trusts e aos hospitais públicos: transformação de serviços para corporations. Os serviços de saúde precisam zerar (break even) seus livros-caixa com um retorno (profit) de pelo menos $6 \%$ ao seu 'dono', o governo. Prestação de contas no modo shareholders, promovendo a ideia de intercâmbio (interchangeability) entre serviços públicos e privados.
3. Contabilidade Comercial (Resource Accounting) como pré-requisito necessário para o estabelecimento de parcerias público-privadas.

4. Iniciativa de Financiamento Privado (Private Finance Initiative): demonstrada à opinião pública como acesso público a recursos privados, na prática, é exatamente o oposto. As 'iniciativas' ou 'parcerias' possibilitam o repasse de recursos públicos a entes privados na condição de que estes realizem melhoramentos/construção de serviços de saúde, retirando o investimento público diretamente de serviços já existentes em prol de state of the art facilities (serviços ditos de última geração tecnológica). Esses novos serviços são cedidos ao NHS mediante contratos de aluguel/empréstimo de longo prazo (da totalidade da instituição ou de parte dela por até 30 anos) junto ao ente privado que realizou a construção/reforma.

A chamada marketisation do sistema de saúde inglês é um tema controverso e ainda pouco entendido, já que o acesso ao sistema de saúde pela população foi moderadamente modificado, assim como a origem do gasto em saúde, que segue sendo predominantemente público. Além disso, a redução do número de profissionais e o aumento de casos acusando falhas no sistema de saúde vêm, gradativamente, municiando policy makers encarregados de privatizar ainda mais o sistema - seja a partir da provisão de saúde por entes privados ou mesmo de pouco perceptíveis mecanismos administrativos (REYNOLDS; MCKEE, 2012).

A economia americana há muito tempo almeja os gastos públicos europeus, não apenas em saúde, mas no setor de seguridade social e em outros serviços. O estabelecimento das negociações de um possível acordo entre Estados Unidos e União Europeia (UE), chamado Transatlantic Trade Investment Partnership (TTIP), preocupa pelo possível aumento da participação de empresas transnacionais americanas, não apenas no setor saúde, enfraquecendo governos, no 
tocante ao controle de seus próprios mercados, em favorecimento às diretivas da União de Estados Europeus ou, mesmo, de outros setores da economia. O descontentamento da população com as atuais políticas de austeridade e diminuição de gastos públicos foi demonstrado parcialmente nas eleições europeias de 2014, tanto para o Parlamento da União Europeia quanto nas escolhas nacionais e locais. Estão presentes discussões de mecanismos de defesa a movimentos independentistas em alguns países membros, assim como no próprio Parlamento Europeu; além da eleição de um governo de esquerda na Grécia, um dos principais focos da crise econômica na UE.

\section{Nomeando os bois - o Investimento Externo ou Foreign Direct Investment (FDI) e seus efeitos no mercado}

Considerada a área mais sensível de negociações relativas ao Gats da OMC, há pouca literatura que aborde o tema, especificamente com relação à saúde. Também, a produção de dados tende a ser polarizada entre argumentos contra ou a favor do FDI nas mais variadas áreas de investimento e conhecimento. Ao abordar, de maneira sistemática, a literatura referente ao setor da saúde, empiricamente, emerge a percepção de uma produção mais intensa a partir da virada do milênio nos chamados países em desenvolvimento (ou tardiamente desenvolvidos), como China, Índia e Nova Zelândia, assim como escassas percepções externas sobre o mercado brasileiro de saúde - algo que deverá mudar com a nova perspectiva de abertura após a mudança da legislação nacional. Em outras palavras, anteriormente, nas raras vezes em que o mercado brasileiro foi mencionado, ele era considerado como de portas fechadas (closed doors) ao investimento estrangeiro (WORLD BANK, 2010).
Smith (2014), ao revisar sistematicamente a literatura sobre FDI no mercado da saúde, aponta três tendências:

i. Quanto à comercialização de serviços, as restrições da população no acesso ao cuidado em saúde são mais relevantes para os sistemas afetados do que, necessariamente, definir se o capital utilizado para financiamento é externo ou local;

ii. Os sistemas de regulação de mercados nacionais determinarão o impacto que o FDI terá na saúde local, a garantia de medidas de proteção (aos cidadãos e ao mercado local) e a estabilidade dos compromissos assumidos pelo país nas rodadas do Gats;

iii. As negociações entre entidades locais e externas dependerão do entendimento comum sobre o que está sendo negociado. Assim, a interpretação mútua de termos-chave nessa relação é de suma importância.

Grifou-se o segundo item por considerá-lo essencial no caso brasileiro. A maneira como o FDI irá impactar o sistema de saúde nacional nos seus subsistemas público e privado é determinada pelos mecanismos de regulação de mercado e de proteção social aos cidadãos. A ausência de negociação com o controle social, com relação à aprovação do $F D I$ no mercado de saúde brasileiro, dá o tom da melodia quanto à (não) regulação.

O estudo de Alsan, Bloom e Canning (2006) considerou os efeitos do FDI não apenas no mercado da saúde, mas em outros serviços e produtos. Os autores demonstram uma relação oposta à que ocorre quando apenas o mercado da saúde é levado em conta, principalmente em países em desenvolvimento (restrição de acesso, aumento de preços etc.). A pesquisa mostra que indicadores gerais, como a expectativa de vida da população ao nascer, a pirâmide etária, entre outros, influenciam diretamente o interesse do capital externo em investir ou não em determinado país. Ao analisarem 74 países de média e baixa renda, os autores apontam que o acréscimo de 1 ano na expectativa de vida geral da população chega a impulsionar o 
investimento estrangeiro em $9 \%$, em valores absolutos. O FDI busca não apenas possíveis margens de lucro provendo serviços, mas, também, mão de obra longeva e de baixo custo voltada para a produção.

\section{Um prelúdio do caso brasileiro}

$\mathrm{O}$ argumento comum na defesa do FDI na saúde, especificamente no caso brasileiro, é o de que tal abertura regulamentaria a Lei 9656/1998 (BRASIL, 1998), promovendo maior competição entre provedores de saúde, acarretando, como consequência benéfica, maior oferta de serviços a preços mais baixos. Nessa assertiva há, porém, de acordo com a literatura científica, uma demasiada simplificação da questão. Já se observou em outros países que a liberalização de serviços necessários à população, como correios, telecomunicações e energia, possui características básicas:

- Necessita efetiva regulamentação por parte do Estado, no sentido da manutenção/ aumento da qualidade e da proteção ao consumidor nos serviços prestados, evitando a formação de monopólio;

- Apresenta alto nível de transparência e accountability, mediante a constante publicação de dados e relatórios anuais;

- Se necessária, a regulamentação estatal interfere no sistema de precificação, evitando sobrecarga (overtariff).

O estabelecimento da Agência Nacional de Saúde Suplementar (ANS) previa uma maior transparência na relação com os planos privados de saúde no Brasil, em 1998. Apesar de alguns avanços, questões cruciais, como o levantamento e a disponibilidade de dados e o ressarcimento ao Sistema Único de Saúde (SUS), frustraram grande parte dessas expectativas. Parcos dados são disponibilizados, e o controle social sobre a ANS é mínimo. O desafio brasileiro na saúde pública ultrapassa a esfera técnica e adentra a questão política (PAIM ET AL., 2012). A própria criação da ANS é motivo de discussão sobre os reais beneficiários e seu controle social.

O caso da possível anistia aos 2 bilhões de reais em dívidas dos planos de saúde, posteriormente vetada pela Presidenta da República, em 2014, ilustra a constante tensão entre os poderes executivo e legislativo no tocante ao tema da participação privada na saúde - discussão constante nas várias instâncias do Congresso Nacional. A experiência da pouca regulamentação da ANS com relação aos planos privados de saúde demonstra a incapacidade do poder executivo e do poder legislativo de favorecer a transparência necessária para que uma real competição entre prestadores se estabeleça. A mínima presença de mecanismos de controle de qualidade de atendimento e a pequena quantidade de dados fornecidos sobre o sistema privado de saúde no Brasil são pouco alvissareiras para um sistema que se propõe a receber o capital estrangeiro, aumentando a competição de maneira desenfreada. $\mathrm{O}$ elo mais fraco dessa corrente é o cidadão que, ao necessitar de cuidados em saúde, se dispuser a tentar comprá-los no mercado.

O apoio do governo ao tema é paradoxal por vários aspectos. Por ser uma medida liberal, ela demonstra a intenção de diminuir o poder das entidades médicas sobre o mercado da saúde brasileiro, o que seria salutar, haja vista as disputas políticas impostas pelo corporativismo médico com relação às ações governistas, como, por exemplo, o Programa Mais Médicos. O cenário nacional é único e não cabe em análises internacionais, portanto, seria apenas um exercício de opinião listar as possíveis razões governistas para aprovar a legislação de abertura do mercado brasileiro ao capital externo. $\mathrm{O}$ discurso é quase que eufemístico ao mencionar uma 'legislação', pois se foi de um extremo ao outro sem a proposta de qualquer tipo de regulamentação. Passou-se da vedação completa para a abertura irrestrita, chamando a atenção a ausência de regulamentação 
da matéria. A principal argumentação é a redução da assimetria de mercado observada no setor privado de saúde. Pois, seguindo tal argumentação, com base na experiência de outros setores de serviços, principalmente os de telefonia e bancários internacionais, são sugeridos três estágios do efeito do $F D I$ no mercado da saúde brasileiro:

$1^{\circ}$ Estágio - curto prazo ( 1 a 2 anos): pequenas fusões em que os players menos capitalizados serão absorvidos por entidades mais capitalizadas, provavelmente, aportadas por investimento externo. Buscas não sistemáticas em bases eletrônicas permitem perceber o entusiasmo do setor jurídico brasileiro com relação ao aquecimento do mercado de fusões na área da saúde, previsto para os próximos 2 anos;

$2^{\circ}$ Estágio - médio prazo ( 3 a 5 anos): o número de competidores tende a diminuir consideravelmente, principalmente à ocasião das intensas quedas de preços, forçando fusões entre provedores maiores que os observados, unindo-se nos dois primeiros anos pós abertura;

$3^{\circ}$ Estágio - longo prazo (5 a 10 anos): o terceiro momento é reservado apenas para os maiores players, os que puderam arcar com as despesas de preços baixos por alguns anos (protegidos pelo investimento externo) e que agora poderão, gradativamente, recuperar os prejuízos dos primeiros anos de fusões e adaptação ao mercado nacional por meio da regulação da oferta.

Possivelmente, o terceiro estágio seria acompanhado de um aumento considerável de preços e de uma maior segmentação do mercado - ainda maior do que a já observada no subsistema privado nacional. Haveria oferta de produtos de cuidado em saúde para a clientela 'certa' (taylored products), segmentando o mercado de acordo com as classes sociais e faixas de preço em uma realidade ainda mais aguda que a observada neste momento no País.

Bahia, ainda em 2001, ao analisar a obscura regulamentação dos planos de saúde no Brasil, mencionou o possível interesse no capital estrangeiro naquele momento:

A versão mais vulgar ou abreviada da intervenção do Estado na assistência médica suplementar para corrigir o mercado é defendida ou atacada por aqueles que julgam que seu propósito final é abrir caminho para as empresas estrangeiras. 'O preceito da abertura para a participação do capital internacional passa a ser encarado como um meio para revitalizar a operação de planos de saúde ou como estratégia de desmonte do mercado nacional'. (BAHIA, 2001, P. 337, GRIFO DO AUTOR).

A análise sintetiza o paradoxal posicionamento do governo no início de 2015 com relação aos seus objetivos quanto à abertura do mercado nacional, a já mencionada resolução da assimetria de mercado. Porém, a resolução a partir de tal abertura desregulamentada parece, em tom coloquial, liquidar a doença com a morte do doente.

Um caso que chama a atenção internacional é o do sistema público de saúde japonês. A quarta maior economia do mundo, de acordo com dados da OMC, em 2014, possui uma das populações mais longevas do globo e protege, apesar da pressão internacional, o seu sistema público de saúde de investimentos externos (PAPRZYCKI, 2006). Apesar das críticas de agentes financeiros internacionais, relacionadas à 'baixa produtividade', quando comparado ao setor hospitalar americano, o sistema assistencial é preservado (ainda que utilizando copagamentos para serviços específicos) e apresenta excelentes indicadores de saúde. A retenção com relação ao investimento externo igualmente retém preços, mantendo um dos mais altos níveis de equidade do mundo (CAMPBELL ET AL., 2012).

As empresas estrangeiras estudam o mercado brasileiro há mais de uma década, porém, a legislação vedava a participação na prestação de serviços, dificultando a entrada do capital. As declarações na imprensa de empresários favoráveis à nova legislação anunciam o
1 Esse é o principal argumento da Ação de Inconstitucionalidade movida contra a Lei 13.097/2015, a qual encontra-se em trâmite durante a escrita deste ensaio. 
que está por vir com relação ao interesse das empresas transnacionais de saúde no Brasil. Já ocorre, neste início de 2015, a prospecção de mercado, e o interesse volta-se às regiões Sul e Sudeste, as mais ricas e saturadas de profissionais e de oferta de serviços do País, derrubando o argumento de maior acesso à saúde no subsetor privado em todo o território nacional.

A formação de blocos de prestadores de serviços, que ocorrerá no terceiro estágio sugerido por este ensaio (longo prazo, 5 a 10 anos), proporcionará a estes o controle da oferta e, consequentemente, do preço dos serviços de saúde. Com pouca capacidade instalada, o serviço público depende dos prestadores privados para a manutenção do SUS nos setores secundários e terciários da oferta, ficando, nesse estágio, refém de preços não regulados, ditados, então, pela dominante oferta privada.

\section{À guisa de conclusão: inviabilização do SUS como sistema universal}

A maior consequência da abertura do mercado de saúde brasileiro para o capital estrangeiro é a inviabilização do SUS como política pública de saúde. A injeção irrestrita de recursos no setor privado 'inviabiliza o Sistema Único de Saúde brasileiro' ao reforçar a assimetria entre os subsistemas público e privado. $\mathrm{O}$ estabelecimento de uma maior concorrência local, a partir de recursos externos, violenta o próprio direito constitucional à saúde $\mathbf{1}$, tendo como consequência o desmanche das áreas secundárias e terciárias do SUS, vistas como setores de maior possível margem de lucro e que sofrem cronicamente de pouco investimento público. Seria essa uma manobra governista, na tentativa, de forma precária, de melhorar a situação dos setores secundários e terciários promovendo a competição entre eles? A qualidade dos serviços privados de saúde, já pouco fiscalizada neste momento, como seria controlada?

Infelizmente, a abertura do mercado ao capital externo na saúde é o estabelecimento institucional de cuidados primários para os pobres e a exploração das doenças das classes média e alta, as quais proporcionarão o lucro buscado pelo investimento externo. Ou o investimento externo é feito sem interesse de retorno? Ingenuidade seria crer que o capital externo investido não será igualmente retornado, com juros, correção e lucro. E o será à custa do SUS, dos bolsos e, muito provavelmente, da saúde de boa parte dos brasileiros.

\section{Referências}

ALONSO, J. M.; CLIFTON, J.; DÍAZ-FUENTES, D. The impact of New Public Management on efficiency: An analysis of Madrid's hospitals. Health Policy, London, v. 113 , n. 3, p. 333-340, mar. 2015

ALSAN, M.; BLOOM, D. E.; CANNING, D. The effect of population health on foreign direct investment inflows to low-and middle-income countries. World Development, London, v. 34, n. 4, p. 613-630, 2006.
BAHIA, L. Planos privados de saúde: luzes e sombras no debate setorial dos anos 90. Ciência \&t Saúde Coletiva, Rio de Janeiro, v. 6, n. 2 p. 329-339, 2001.

BRASIL. Presidência da República . Lei no ${ }^{\circ}$ 8.080, de 19 de setembro de 1990. Dispõe sobre as condições para a promoção, proteção e recuperação da saúde, a organização e o funcionamento dos serviços correspondentes e dá outras providências. Diário Oficial [da] União. Brasília, DF, 21 set. 1990. Disponível em: 
<http://www.planalto.gov.br/ccivil_03/Leis/L8080. htm>. Acesso em: 24 out. 2015.

Presidência da República. Lei no 13.097 de 19 de janeiro de 2015. Reduz a zero as alíquotas da Contribuição para o PIS/PASEP, da COFINS, da Contribuição para o PIS/Pasep-Importação e da CofinsImportação incidentes sobre a receita de vendas e na importação de partes utilizadas em aerogeradores; prorroga os benefícios previstos nas Leis $\mathrm{n}^{\text {os }} 9.250$, de 26 de dezembro de 1995, 9.440, de 14 de março de 1997, 10.931, de 2 de agosto de 2004, 11.196, de 21 de novembro de 2005, 12.024, de 27 de agosto de 2009, e 12.375, de 30 de dezembro de 2010; altera o art. 46 da Lei n 12.715, de 17 de setembro de 2012, que dispõe sobre a devolução ao exterior ou a destruição de mercadoria estrangeira cuja importação não seja autorizada; altera as Leis nos 9.430 , de 27 de dezembro de 1996, 12.546, de 14 de dezembro de 2011, 12.973, de 13 de maio de 2014, 9.826, de 23 de agosto de 1999, 10.833, de 29 de dezembro de 2003, 10.865, de 30 de abril de 2004, 11.051, de 29 de dezembro de 2004, 11.774, de 17 de setembro de 2008, 10.637, de 30 de dezembro de 2002, 12.249, de 11 de junho de 2010, 10.522, de 19 de julho de 2002, 12.865, de 9 de outubro de 2013, 10.820, de 17 de dezembro de 2003, 6.634, de 2 de maio de 1979, 7.433, de 18 de dezembro de 1985, 11.977, de 7 de julho de 2009, 10.931, de 2 de agosto de 2004, 11.076, de 30 de dezembro de 2004, 9.514, de 20 de novembro de 1997, 9.427, de 26 de dezembro de 1996, 9.074, de 7 de julho de 1995, 12.783, de 11 de janeiro de 2013, 11.943, de 28 de maio de 2009, 10.848, de 15 de março de 2004 , 7.565, de 19 de dezembro de 1986, 12.462, de 4 de agosto de 2011, 9.503, de 23 de setembro de 1997, 11.442, de 5 de janeiro de 2007, 8.666, de 21 de junho de 1993, 9.782, de 26 de janeiro de 1999, 6.360, de 23 de setembro de 1976, 5.991, de 17 de dezembro de 1973, 12.850, de 2 de agosto de 2013, 5.070, de 7 de julho de 1966, 9.472, de 16 de julho de 1997, 10.480, de 2 de julho de 2002, 8.112, de 11 de dezembro de 1990, 6.530, de 12 de maio de 1978, 5.764, de 16 de dezembro de 1971, 8.080, de 19 de setembro de 1990, 11.079, de 30 de dezembro de 2004, 13.043, de 13 de novembro de 2014, 8.987, de 13 de fevereiro de 1995 , 10.925 , de 23 de julho de 2004, 12.096, de 24 de novembro de 2009, 11.482, de 31 de maio de 2007, 7.713, de 22 de dezembro de 1988, a Lei Complementar n 123, de 14 de dezembro de 2006, o Decreto-Lei no 745 , de 7 de agosto de 1969, e o Decreto n 70.235, de 6 de março de 1972; revoga dispositivos das Leis nos 4.380 , de 21 de agosto de 1964, 6.360, de 23 de setembro de 1976, 7.789, de 23 de novembro de 1989, 8.666, de 21 de junho de 1993, 9.782, de 26 de janeiro de 1999, 10.150, de 21 de dezembro de 2000, 9.430, de 27 de dezembro de 1996, 12.973, de 13 de maio de 2014, 8.177, de $1^{\circ}$ de março de 1991, 10.637, de 30 de dezembro de 2002, 10.833, de 29 de dezembro de 2003, 10.865, de 30 de abril de 2004, 11.051, de 29 de dezembro de 2004 e 9.514, de 20 de novembro de 1997, e do Decreto-Lei n 3.365, de 21 de junho de 1941; e dá outras providências. Diário Oficial [da] União, Brasília, DF, 21 jan. 2015. Disponível em: <http://www.planalto. gov.br/ccivil_03/_ato2015-2018/2015/lei/L13097.htm> Acesso em: 24 out. 2015.

Presidência da República. Lei no 9.656, de 3 de junho de 1998 . Dispõe sobre os planos e seguros privados de assistência à saúde. Diário Oficial [da] União. Brasília, DF, 4 jul. 1998. Dosponível em: < http://www.planalto.gov. br/ccivil_03/Leis/L9656.htm>. Acesso em: 24 out. 2015.

CAMPBELL, J. C.; IKEGAMI, N. The art of balance in health policy: maintaining Japan's low-cost, egalitarian system. Cambridge: Cambridge University Press, 1998.

JARMAN, H. Healthcare, borders, and boundaries: Crossborder health markets and the entrepreneurial state. Policy and Society, New York, v. 33, n. 1, p. 1-11, 2014

KOIVUSALO, M.; TRITTER, J. Trade Creep and Implications of the Transatlantic Trade and Investment Partnership Agreement for the United Kingdom National Health Service. International Journal of Health Services, Los Angeles, v. 44, n. 1, p. 93-111, 2014.

PAIM, J. et al. O sistema de saúde brasileiro: história, avanços e desafios. 2012. Disponível em: <http://www. thelancet.com/journals/lancet/article/PIIS01406736(11)60054-8/references>. Acesso em: 24 nov. 2015.

PAPRZYCKI, R. The impact of foreign direct investment in Japan: case studies of the automobile, finance, and health care industries. Hi-Stat Discussion Paper, New York, n. 141, 2006

POLLOCK, A. M.; PRICE, D. Duty to care: in defence of universal health care. 2013. Disponivel em: <https://www. 
google.com.br/url?sa=t\&rct=j\&q=\&esrc=s\&source=we $\mathrm{b} \& \mathrm{~cd}=1 \& v e d=0$ ahUKEwjAyJOi2KvJAhUHNJAKHclT CasQFggeMAA\&url=http\%3A\%2F\%2Fclassonline.org. uk\%2Fdocs\%2F2013_05_Policy_Paper_-_A_duty_to_care_ (Allyson_Pollock_David_Price).pdf\&usg=AFQjCNHfGW SsAVUg4BZkCQp7gmIjB_OyEg\&sig2=bHFKhxgiOGhuuMsqKFvPQ>. Acesso em: 24 nov. 2015.

PRICE, D.; POLLOCK, A.; SHAOUL, J. How the World Trade Organisation is shaping domestic policies in health care. The Lancet, London, n. 354, p. 1889-1892, 1999.

REEVES, A. et al. The political economy of austerity and healthcare: cross-national analysis of expenditure changes in 27 European nations 1995-2011. Health Policy, v. 115, n. 1, p. 1-8, 2014.

REYNOLDS, L.; MCKEE, M. Opening the oyster: the 2010-11 NHS reforms in England. Clinical medicine, London, v. 12, n. 2, p. 128-132, 2012.

SMITH, R. D. Foreign direct investment and trade in health services: a review of the literature. Social Science \& Medicine, Oxford, v. 59, n. 11, p. 2313-2323, 2014.
VANBERG, V. J. Darwinian paradigm, cultural evolution and human purposes: on FA Hayek's evolutionary view of the market. Journal of Evolutionary Economics, Sacramento, v. 24, n. 1, p. 35-57, 2014.

WALLACH, L.; WOODALL, P. Whose trade organization?: a comprehensive guide to the WTO. New York: New Press, 2004.

WORLD BANK. Investing Accross Borders: indicators of foreign direct investment regulation in 87 economies. 2010. Disponível em: <https://www. google.com.br/url?sa=t\&rct=j\&q=\&esrc=s\&source= web $\& c d=3 \& c a d=$ rja $\&$ uact $=8 \&$ ved $=0$ ahUKEwjil $\mathrm{Njq}$ 2KvJAhWHn5AKHY8wBNkQFgg0MAI\&url=http \%3A\%2F\%2Fiab.worldbank.org\%2F \%2Fmedia\%2 FFPDKM\%2FIAB\%2FDocuments\%2FIAB-report. pdf\&usg=AFQjCNEzcGlvgYKAxek2_LxhoWu2BjY pw\&sig2=KVYhJvI8FcYQKNEYsJNHuQ>. Acesso em: 24 nov. 2015.

Recebido para publicação em abril de 2015

Versão final em setembro de 2015

Conflito de interesses: inexistente

Suporte financeiro: não houve 